\title{
Effects of a proposed physical activity and diet control to manage constipation in middle-aged obese women
}

\author{
Sayed A Tantawy ${ }^{1,2}$ \\ Dalia M Kamel ${ }^{2,3}$ \\ Walid Kamal Abdelbasset $t^{4,5}$ \\ Hany M Elgohary ${ }^{6}$ \\ 'Department of Physiotherapy, Centre \\ of Radiation, Oncology and Nuclear \\ Medicine, Cairo University, Giza, \\ Egypt; ${ }^{2}$ Department of Physiotherapy, \\ College of Medical and Health \\ Sciences, Ahlia University, Manama, \\ Kingdom of Bahrain; ${ }^{3}$ Department \\ of Physiotherapy of Obstetrics and \\ Gynecology, Faculty of Physical \\ Therapy, Cairo University, Giza, Egypt; \\ ${ }^{4}$ Department of Physical Therapy \\ and Health Rehabilitation, College \\ of Applied Medical Sciences, Prince \\ Sattam Bin Abdul Aziz University, \\ Alkharj, Saudi Arabia; ${ }^{5}$ Department \\ of Physical Therapy, Kasr Al-Aini \\ Hospital, Cairo University, Cairo, \\ Egypt; ${ }^{6}$ Department of Physical \\ Therapy for Surgery, Faculty of \\ Physical Therapy, Cairo University, \\ Giza, Egypt
}

This article was published in the following Dove Press journal: Diabetes, Metabolic Syndrome and Obesity:Targets and Therapy

Background: Obesity is very common worldwide and is related to critical morbidity and mortality. It has a large number of impacts on the human body. Constipation has a prevalence from $4 \%$ to $29 \%$ in various parts of the world and is considered to be a major health problem, with an estimated incidence of $5 \%$ in males and $15 \%$ in females. There is a strong association between obesity and constipation. This study aimed to investigate the effect of physical activity and a low-calorie diet on constipation in middle-aged obese women.

Methods: This study included 125 obese women (age 20-40 years) who had chronic constipation. Participants were randomly assigned to two groups. Group A included 62 women who received a suggested protocol of physical activity, a low-calorie diet, and the routine standard care for constipation, whereas Group B included 63 women who received only the standard medical care for constipation and a low-calorie diet. Both groups followed the program for 12 weeks. Changes in the Patient Assessment of Constipation Symptoms (PAC-SYM) and Patient Assessment Quality of Life (PAC-QOL) scores, and in the body mass index (BMI) were recorded in study subjects, both at baseline and at the end of the study program.

Results: There were no statistically significant differences in the baseline characteristics of patients in the two groups. After 12 weeks of intervention, both groups showed significant intragroup differences $(p<0.05)$ in all of the measured variables, except the BMI which showed a nonsignificant difference $(p>0.05)$ in Group B. Between-groups comparison showed significant differences $(p<0.05)$ in all of the measured parameters in favor of Group A.

Conclusion: Physical activity and weight reduction improve PAC-SYM and PAC-QOL scores in middle-aged, premenopausal women with constipation in the short term (up to 12 weeks).

Keywords: constipation, physical activity, obesity, low-calorie diet, patient assessment quality of life

\section{Introduction}

Constipation is a worldwide condition affecting individuals of all ages, with prevalence ranging from $4 \%$ to $29 \%$ in various parts of the world. ${ }^{1-4}$ Gender-wise comparisons reveal that women, particularly premenopausal women, experience constipation more often than men, ${ }^{5,6}$ with an estimated $5 \%$ of the male and $15 \%$ of the female population being affected. ${ }^{2}$ This indicates that women are 2 to 3 times more likely to suffer from constipation than men. ${ }^{7}$ The physiologic reason behind this female predominance is unclear; however, some studies have concentrated on female sex hormones as a potential reason for this gender difference. ${ }^{3,6}$ Several women experience changes in bowel habits (ie, looser consistency) with the onset of menses $^{2}$ when progesterone and estradiol levels significantly decline, thus, bringing about the feminine cycle ${ }^{8}$ In contrast, prolongation
Correspondence: Sayed A Tantawy Department of Physiotherapy, College of Medical Health and Sciences, Ahlia University, P.O. Box 10878 Manama, Kingdom of Bahrain

Tel +97336883977

$\mathrm{Fax}+97317290083$

Emailsmosa@ahlia.edu.bh 
of orocecal transit time is observed during the luteal stage. ${ }^{9}$ In addition, constipation is common during the second and third trimesters of pregnancy, when progesterone and estradiol levels are considerably elevated. ${ }^{10}$ However, pregnancy also brings many changes, including the gravid uterus that compresses the intestines; therefore, pregnancy-induced constipation cannot be attributed to the effects of progesterone alone. In fact, there is controversy regarding the impact of sex steroids on colonic transit, as a previous study reported no significant differences in colonic transit between any of the phases of the menstrual cycle. Although colonic transit in women was slower than in men, this was not statistically significant. ${ }^{11}$ Moreover, estradiol and a combination of sex steroids do not have a beneficial impact on colonic transit in postmenopausal women. ${ }^{12}$ Further, the damage to pelvic floor muscles during childbirth or gynecological surgeries is another risk factor in women. ${ }^{3}$ Constipation can be managed by lifestyle modifications, through increasing the consumption of dietary fibers and fluids, and increasing physical activity. Pharmacological treatment is another way to manage constipation - through stool softeners, bulk-forming agents, osmotic agents, and chloride channel activators. Some chronic cases can be treated by probiotics and surgery. ${ }^{7}$ Several studies have also shown the positive effect of moderate-intensity exercise on stool consistency and frequency. ${ }^{4,13,14}$

The exercise dose effect is a very important factor that should be considered, as mild to moderate physical activity showed positive effects on the health of the gastrointestinal tract (GIT), evidenced as a decrease in liver enzymes in obese patients with hepatitis $\mathrm{C}$ infection, ${ }^{15}$ and reduced incidence of liver disease, ${ }^{16}$ cholelithiasis, ${ }^{17}$ colon cancer, ${ }^{16}$ and constipation ${ }^{18}$ in addition to decreased C-reactive protein (CRP), an inflammatory marker, in obese women. ${ }^{19}$ In contrast, acute vigorous exercise could provoke nausea, vomiting, diarrhea, gastrointestinal (GI) bleeding, and heartburn. ${ }^{20}$ In addition, compared to physically inactive individuals, physically active individuals have demonstrated a lower prevalence of constipation. ${ }^{21}$

\section{Methods}

This study, conducted from December 2015 to November 2016, was approved by the Research Ethical Committee of the Faculty of Physical Therapy, Cairo University (No P.T. REC/ 012/001542), and was a registered randomized controlled clinical trial at Clinicaltrial.gov with identifier number (NCT02745652). In total, 125 women (age 20-40 years) were recruited into this study. Participants were considered eligible if they met the inclusion criteria of being diagnosed with functional constipation, as defined by the Rome Foundation.
Patients whose BMI exceeded $30 \mathrm{~kg} / \mathrm{m}^{2}$ were included. In addition, subjects fulfilled the ROM criteria of constipation, as follows: 1) Suffered from any two or more of the following symptoms in the past 12 weeks (not necessarily consecutive), with symptom-onset at least 6 months prior to diagnosis: a) straining during at least $25 \%$ of defecations, b) lumpy or hard stools in at least $25 \%$ of defecations, c) sensation of incomplete evacuation for at least $25 \%$ of defecations, d) sensation of anorectal obstruction/blockage for at least $25 \%$ of defecations, e) requirement of manual maneuvers to facilitate at least $25 \%$ of defecations (eg, digital evacuation, support of the pelvic floor muscles), and f) fewer than three defecations per week; 2) loose stools rarely occurred without the use of laxatives; 3 ) insufficient criteria for irritable bowel syndrome; and 4) women were sedentary ( $<1$ hour/week of physical activity), with no evidence of participation in diet control/weight reduction programs within the last 6 months.

Patients with metabolic, endocrine, and neurologic constipation; current or past smokers; those with any orthopedic limitation; and those with congenital megacolon, pseudo-obstruction, and anorectal disorders were excluded from the study. Patients suffering from constipation due to drugs, disabled patients, and those who had undergone any abdominal surgery during the intervention or those who failed to complete the study protocol were also excluded. All participants provided written informed consent for study participation before enrolling in the study.

\section{Study design and intervention}

Participants were randomly divided into two groups. Group A included 62 women who were following a suggested protocol of physical activity and a low-calorie diet in addition to the routine standard care for constipation. The low-calorie diet allowed 1,000-1,200 kcal/day, divided as follows: 50\%-60\% carbohydrates, $20 \%$ protein, $<30 \%$ total fat, and $18 \mathrm{~g}$ of fiber/1,000 kcal. The diet plans were revised every 2 weeks, and the diet was modified while ensuring that it was within the allowed caloric value, in addition to the routine standard care for constipation. Group B included 63 patients who received only the standard medical care for constipation and a low-calorie diet as in Group A. Patients in both groups followed their program for 12 weeks.

\section{Exercise intervention for Group A}

Each woman in Group A participated in the exercise training program for 12 weeks, 3 times per week, with each exercise session lasting 60 minutes. Participants were instructed not to eat for 3 hours before the exercise session. 
The exercise training program was in the form of walking on a treadmill without tightly grasping the rails, because this action seemed to reduce the workload during any stage of the exercise. To overcome this issue, the participants were asked to remove their hands from the rails, close their fists, and place only one finger on the rails to maintain balance once they were accustomed to walking on the treadmill.

The exercise session was started by a 10-minute warmup, which involved walking without any resistance or inclination on the walkway of the treadmill, followed by 40 minutes of walking with 15 degrees of inclination and a speed adjusted to reach $20 \%-40 \%$ of the target heart rate (THR) in the first 6 weeks of the study; the speed was increased to reach $40 \%-60 \%$ THR in the next 6 weeks of the study. The session ended with 10 minutes of recovery period, in which the intensity of the exercise was reduced to the level of the warm-up.

The assessment procedures performed before and after 12 weeks of intervention consisted of the following:

- The Patient Assessment of Constipation - Symptom (PAC-SYM) is a reliable and valid ${ }^{22,23}$ tool to measure the patient's perspective of constipation symptoms in terms of the frequency and severity. It is a 12-item self-reported measure, which is divided into three manifestation subscales (ie, abdominal, rectal, and stool). Items are scored on a 4-point Likert scale, with a score of 4 demonstrating the worst symptom severity. ${ }^{24,25}$

- The Patient Assessment of Constipation Quality of Life (PAC-QOL) is a comprehensive measure of the constipation burden on the patient's quality of life (QOL) in terms of functions, activities, and well-being. It is considered a valid and reproducible tool with high internal consistency. ${ }^{26}$

- The Short Form-36 (SF-36) is well validated, reliable, not time- or effort-intensive, and has been presented in several international studies. ${ }^{27-29} \mathrm{It}$ is a 36 -item questionnaire that measures the QOL across eight scales (domains), which are based on both physical and emotional aspects. The eight domains of the SF-36 are concerned with the following: physical functioning, role limitations owing to physical health or emotional problems, energy/fatigue, emotional wellbeing, social functioning, pain, and general health. In addition, a single item is included to identify any perceived change in health, making the SF-36 a useful indicator for change in QOL over time and treatment. The scores of the SF-36TM physical component summary and SF-36TM mental component summary are calculated by simply calculating the mean score of all of the physically and emotionally relevant items. ${ }^{29-31}$

Descriptive statistics were calculated as the mean and standard deviation. Inferential statistics evaluated the changes in constipation symptoms, QOL questionnaires, and BMI using the unpaired $t$-test between the two groups, while the paired $t$-test was used to measure the changes within a group. Pearson correlation coefficient was used to measure the strength and direction of the relationship between BMI and PAC-SYM scores, and between BMI and QOL. All data were analyzed using SPSS version 18.0 (SPSS, Chicago, IL, USA), with statistical significance set at $p \leq 0.05$.

\section{Results}

In total, 125 women with functional constipation were included in this study. Participants were assigned to study group (Group A) and control group (Group B). Women in Group A were advised physical activity and a low-calorie diet in addition to receiving the standard medical care for constipation, whereas those in Group B received only the standard medical care for constipation and a low-calorie diet. At the beginning of the study, before intervention, there were no statistically significant differences between patients in both groups in terms of age, height, weight, BMI, PAC-SYM scores, and PAC-QOL questionnaire scores, with $p>0.05$. Demographic and clinical characteristics of patients in both groups are described in Table 1. These data reveal that the patients in both groups had similar clinical characteristics.

The main findings of this study showed that all measurements were significantly improved at the end of the study period among patients in both groups, except for BMI, which decreased only among patients in Group A. As reported in Tables 2 and 3, the percentage of change of BMI in Group A was $11.3 \%$, whereas it was $5.6 \%$ in Group B. This decrease in BMI among patients in Group A after 12 weeks of intervention is shown in Table 4.

Statistically significant improvement in PAC-SYM scores, including the overall, stool, abdominal, and rectal scores, was observed among patients in both groups. Changes in scores among patients in Group A were 33.8\%, 29.5\%, 37.6\%, and $54.6 \%$, respectively, whereas changes in scores among patients in Group B were 21.8\%, 16.73\%, 23.6\%, and 28.0\%, respectively. When patients in both groups were compared, those in Group A showed greater improvement in PAC-SYM scores, as presented in Tables 2 and 3, and the improvement in scores after the 12-week intervention is reported in Table 4. 
Table I Demographic and clinical characteristics of patients in both groups (A\&B)

\begin{tabular}{|c|c|c|c|}
\hline \multirow[t]{2}{*}{ Items } & \multirow{2}{*}{$\begin{array}{l}\text { Group A }(n=62) \\
\text { Mean } \pm \text { SD }\end{array}$} & \multirow{2}{*}{$\begin{array}{l}\text { Group B }(n=63) \\
\text { Mean } \pm \text { SD }\end{array}$} & \multirow[t]{2}{*}{ p-value } \\
\hline & & & \\
\hline Age (years) & $33.25 \pm 5.23$ & $34.75 \pm 4.43$ & 0.09 \\
\hline Height (cm) & $172 \pm 2.7$ & $|7| \pm 3.4$ & 0.07 \\
\hline Weight (kg) & $81.4 \pm 4.5$ & $82.8 \pm 6.3$ & 0.16 \\
\hline BMI $\left(\mathrm{kg} / \mathrm{m}^{2}\right)$ & $27.5 \pm 2.5$ & $28.3 \pm 3.2$ & 0.12 \\
\hline Overall PAC-SYM symptoms score & $1.98 \pm 0.46$ & $2.02 \pm 0.51$ & 0.65 \\
\hline PAC-SYM stool symptoms score & $2.34 \pm 0.55$ & $0.41 \pm 2.39$ & 0.57 \\
\hline PAC-SYM abdominal symptoms score & $0.37 \pm 1.94$ & $0.23 \pm 1.99$ & 0.37 \\
\hline PAC-SYM rectal symptoms score & $1.19 \pm 0.33$ & $0.24 \pm 1.21$ & 0.70 \\
\hline Overall PAC-QOL score & $2.12 \pm 0.44$ & $2.15 \pm 0.19$ & 0.62 \\
\hline PAC-QOL psychosocial discomfort score & $1.19 \pm 0.23$ & $1.21 \pm 0.35$ & 0.71 \\
\hline PAC-QOL physical discomfort score & $2.44 \pm 0.76$ & $2.48 \pm 0.47$ & 0.72 \\
\hline SF-36 ${ }^{\mathrm{TM}}$ PCS score & $46.5 \pm 1.29$ & $46.7 \pm 1.54$ & 0.43 \\
\hline SF-36 $6^{\mathrm{TM}}$ MCS score & $45.4 \pm 1.32$ & $45.8 \pm 1.43$ & 0.11 \\
\hline
\end{tabular}

Abbreviations: SD, standard deviation; P, probability; PAC-SYM, Patient Assessment of Constipation - Symptoms questionnaire; PAC-QOL, Patient Assessment of Constipation - Quality Of Life questionnaire; SF- 36 ${ }^{\mathrm{TM}}$, 36-item Short Form Health Survey; PCS, Physical Component Summary of the SF-36 ${ }^{\mathrm{TM}}$ questionnaire; MCS, Mental Component Summary of the SF- $36^{\mathrm{TM}}$ questionnaire.

Table 2 Statistical analysis of mean differences in Group (A) pre- and post-intervention

\begin{tabular}{|c|c|c|c|c|}
\hline Items & $\begin{array}{l}\text { Pre- } \\
\text { Mean } \pm \text { SD }\end{array}$ & $\begin{array}{l}\text { Post- } \\
\text { Mean } \pm \text { SD }\end{array}$ & $p$-value & $\%$ of changes \\
\hline BMI $\left(\mathrm{kg} / \mathrm{m}^{2}\right)$ & $27.5 \pm 2.5$ & $24.4 \pm 2.29$ & $0.02^{*}$ & 11.3 \\
\hline Overall PAC-SYM score & $1.98 \pm 0.46$ & $1.31 \pm 0.24$ & $0.02 *$ & 33.8 \\
\hline PAC-SYM stool score & $2.34 \pm 0.55$ & $\mathrm{I} .65 \pm 0.34$ & $0.02^{*}$ & 29.5 \\
\hline PAC-SYM abdominal score & $0.37 \pm 1.94$ & $0.17 \pm 1.21$ & $0.0 I^{*}$ & 37.6 \\
\hline PAC-SYM rectal score & $1.19 \pm 0.33$ & $0.54 \pm 0.21$ & $0.005^{*}$ & 54.6 \\
\hline Overall PAC-QOL score & $2.12 \pm 0.44$ & $1.38 \pm 0.53$ & $0.02 *$ & 34.9 \\
\hline PAC-QOL psychosocial discomfort score & $1.19 \pm 0.23$ & $0.67 \pm 0.18$ & $0.0 I^{*}$ & 43.6 \\
\hline PAC-QOL physical discomfort score & $2.44 \pm 0.76$ & $\mathrm{I} .47 \pm 0.82$ & $0.0 I^{*}$ & 39.7 \\
\hline SF-36 ${ }^{\mathrm{TM}}$ PCS score & $46.5 \pm 1.29$ & $49.6 \pm 3.14$ & $0.03^{*}$ & 6.6 \\
\hline SF-36 ${ }^{\text {TM }}$ MCS score & $45.4 \pm 1.32$ & $49.2 \pm 2.21$ & $0.02 *$ & 8.4 \\
\hline
\end{tabular}

Note: *means significant.

Abbreviations: SD, standard deviation; P, probability; PAC-SYM, Patient Assessment of Constipation - Symptoms questionnaire; PAC-QOL, Patient Assessment of Constipation - Quality Of Life questionnaire; SF-36 ${ }^{\mathrm{TM}}$, 36-item Short Form Health Survey ${ }^{\mathrm{TM}}$; PCS, Physical Component Summary of the SF-36 ${ }^{\mathrm{TM}}$ questionnaire; MCS, Mental Component Summary of the SF-36 ${ }^{\mathrm{TM}}$ questionnaire.

Table 3 Statistical analysis of mean differences in Group (B) pre- and post-intervention

\begin{tabular}{|c|c|c|c|c|}
\hline Items & $\begin{array}{l}\text { Pre- } \\
\text { Mean } \pm \text { SD }\end{array}$ & $\begin{array}{l}\text { Post- } \\
\text { Mean } \pm \text { SD }\end{array}$ & $p$-value & $\%$ of changes \\
\hline BMI $\left(\mathrm{kg} / \mathrm{m}^{2}\right)$ & $28.3 \pm 3.2$ & $26.7 \pm 3.21$ & 0.06 & 5.6 \\
\hline Overall PAC-SYM score & $2.02 \pm 0.51$ & $1.58 \pm 0.44$ & $0.03 *$ & 21.8 \\
\hline PAC-SYM stool score & $0.41 \pm 2.39$ & $1.99 \pm 0.21$ & $0.02 *$ & 16.73 \\
\hline PAC-SYM abdominal score & $0.23 \pm 1.99$ & $0.31 \pm 1.52$ & $0.0 I^{*}$ & 23.6 \\
\hline PAC-SYM rectal score & $0.24 \pm 1.21$ & $0.87 \pm 0.33$ & $0.02 *$ & 28.0 \\
\hline Overall PAC-QOL score & $2.15 \pm 0.19$ & $1.67 \pm 0.36$ & $0.02 *$ & 22.3 \\
\hline PAC-QOL psychosocial discomfort score & $1.21 \pm 0.35$ & $0.88 \pm 0.17$ & $0.0 I^{*}$ & 27.3 \\
\hline PAC-QOL physical discomfort score & $2.48 \pm 0.47$ & $1.93 \pm 0.76$ & $0.0 I^{*}$ & 22.2 \\
\hline SF-36 ${ }^{\mathrm{TM}}$ PCS score & $46.7 \pm 1.54$ & $48.6 \pm 2.33$ & $0.04 *$ & 4.1 \\
\hline SF-36 ${ }^{\mathrm{TM}}$ MCS score & $45.8 \pm 1.43$ & $47.1 \pm 2.41$ & $0.02 *$ & 2.8 \\
\hline
\end{tabular}

Note: *means significant.

Abbreviations: SD, standard deviation; P, probability; PAC-SYM, Patient Assessment of Constipation - Symptoms questionnaire; PAC-QOL, Patient Assessment of Constipation - Quality Of Life questionnaire; SF-36 $6^{\mathrm{TM}}$, 36-item Short Form Health Survey ${ }^{\mathrm{TM}}$; PCS, Physical Component Summary of the SF-36 ${ }^{\mathrm{TM}}$ questionnaire; MCS, Mental Component Summary of the SF-36 ${ }^{\mathrm{TM}}$ questionnaire. 
Table 4 Statistical analysis of mean differences between both groups (A and B) at the end of the intervention

\begin{tabular}{|c|c|c|c|}
\hline Items & $\begin{array}{l}\text { Group A } \\
\text { Mean } \pm \text { SD }\end{array}$ & $\begin{array}{l}\text { Group B } \\
\text { Mean } \pm \text { SD }\end{array}$ & $p$-value \\
\hline BMI $\left(\mathrm{kg} / \mathrm{m}^{2}\right)$ & $24.4 \pm 2.29$ & $26.7 \pm 3.21$ & $0.05^{*}$ \\
\hline Overall PAC-SYM symptoms score & $\mathrm{I} .3 \mathrm{I} \pm 0.24$ & $1.58 \pm 0.44$ & $0.02 *$ \\
\hline PAC-SYM stool symptoms score & $1.65 \pm 0.34$ & $1.99 \pm 0.21$ & $0.01 *$ \\
\hline PAC-SYM abdominal symptoms score & $0.17 \pm 1.21$ & $0.31 \pm 1.52$ & $0.01 *$ \\
\hline PAC-SYM rectal symptoms score & $0.54 \pm 0.21$ & $0.87 \pm 0.33$ & $0.01 *$ \\
\hline Overall PAC-QOL score & $1.38 \pm 0.53$ & $1.67 \pm 0.36$ & $0.02 *$ \\
\hline PAC-QOL psychosocial discomfort score & $0.67 \pm 0.18$ & $0.88 \pm 0.17$ & $0.0 I^{*}$ \\
\hline PAC-QOL physical discomfort score & $1.47 \pm 0.82$ & $1.93 \pm 0.76$ & $0.0 I^{*}$ \\
\hline SF-36 ${ }^{\text {TM }}$ PCS score & $49.6 \pm 3.14$ & $48.6 \pm 2.33$ & $0.03 *$ \\
\hline SF-36 ${ }^{\text {TM }}$ MCS score & $49.2 \pm 2.21$ & $47.1 \pm 2.41$ & $0.01 *$ \\
\hline
\end{tabular}

Note: *means significant.

Abbreviations: SD, standard deviation; P, probability; PAC-SYM, Patient Assessment of Constipation - Symptoms questionnaire; PAC-QOL, Patient Assessment of Constipation - Quality Of Life questionnaire; SF-36 ${ }^{\text {TM }}$, 36-item Short Form Health Survey ${ }^{\text {TM}}$; PCS, Physical Component Summary of the SF-36 ${ }^{\text {TM }}$ questionnaire; MCS, Mental Component Summary of the SF-36 ${ }^{\mathrm{TM}}$ questionnaire.

Further, a statistically significant improvement was observed in the QOL of patients, including the overall quality, psychosocial discomfort, physical discomfort, and SF-36 (physical and mental aspects) scores, in both groups. Changes among patients in Group A were 34.9\%, 43.6\%, 39.7\%, 6.6\%, and $8.4 \%$, respectively, whereas changes among patients in Group B were $22.3 \%, 27.3 \%, 22.2 \%, 4.1 \%$, and $2.8 \%$, respectively. Intergroup comparison showed that patients in Group A presented greater improvement in the QOL, as shown in Tables 2 and 3, and the improvement after the 12-week intervention is presented in Table 4.

Statistical analysis of the correlation coefficient revealed a strong positive correlation between BMI and constipation symptoms $(0.81,0.76,0.82$, and 0.85$)$ in the overall, stool, abdominal, and rectal scores, respectively. A strong correlation was also observed between BMI and QOL $(0.77,0.74$, $0.80,0.78$, and 0.75 ) in the overall, satisfaction, psychosocial discomfort, physical discomfort, and worries and concerns scores, respectively. This indicated that BMI scores have a direct correlation with PAC-SYM and QOL scores.

\section{Discussion}

This study aimed to investigate the effect of 12 weeks of physical activity on improvement of idiopathic constipation in obese premenopausal women. Significant improvement was observed in the condition of women in both study and control groups. Between-groups comparisons showed significant improvement in the PAC-SYM and PAC-QOL, with significant reduction in the BMI in the favor of Group A.

The improvement in the PAC-SYM scores observed in the current study was in line with many studies ${ }^{14,32-35}$ that showed that physical activity exerts positive effects on constipation.
The exact mechanism by which exercise helps in managing and preventing constipation is still unclear. ${ }^{36}$ Some of the underlying mechanisms suggested that exercise affects colonic motility and accelerates gut transit. This exercise effect has been attributed to vagus nerve stimulation and/ or decrease of blood flow to the GI tract; this increases the release of important GI hormones. Another explanation is the mechanical stimulation of the gut during physical activity such as bouncing, upright posture, gravity, and contraction of the abdominal muscles. This mechanical stimulation helps stools to move into the rectum, thus adding to the stimulation; the increase in energy expenditure during physical activity was found to influence energy intake and, therefore, the need for increasing dietary fiber intake. ${ }^{37-39}$

In middle-aged inactive subjects ( $84.4 \%$ of whom were women) with symptoms of chronic constipation, regular physical activity improved both the defecation pattern and the recto-sigmoid or total colonic transit time..$^{32}$ Moreover, in adolescents, constipation was associated with insufficient physical activity and excessive sedentary behavior. In such patients, constipation could be prevented by increasing physical activity. ${ }^{14}$ In the current study, the regular physical activity of the participants was walking at $40 \%-60 \%$ THR. This was similar to a previous study which reported that walking for an hour every day at $60 \%$ of the maximum heart rate improves the condition of sedentary young individuals who suffer from chronic constipation. ${ }^{33}$ Further, in the present study, participants received additional dietary modifications with $18 \mathrm{~g}$ of fiber $/ 1,000 \mathrm{kcal}$; the diet was revised every 2 weeks. The dietary modification was supported by moderate physical activity. Increased fiber intake has been associated with substantial reduction in the prevalence of constipation in women. ${ }^{34}$ In addition, the lack of dietary 
fibers known as non-starch polysaccharides plays an important role in the etiology of constipation, ${ }^{40}$ and consumption of a medium amount of dietary fibers is associated with a lower prevalence of constipation. ${ }^{41}$ Dietary fibers increase fecal volume and bacterial mass, leading to softening of the stools and an increase in their size, which helps maintain regular stool patterns and defecation. Additionally, fiber intake increases colonic motility through the products of bacterial fermentation. ${ }^{37,42}$

In this study, the BMI of women in Group A significantly reduced and showed significant correlation with both PAC-SYM scores and PAC-QOL scores $(r=0.81$ and $r=0.77$, respectively). This is in contrast with a previous study that showed no significant correlation between constipation and BMI; however, the subjects in this previous study were younger than 25 years with BMI in the normal range. ${ }^{33}$ However, the current result is in agreement with the result reported in a previous study that found a correlation between constipation and BMI in middle-aged and elderly individuals. ${ }^{43}$ Therefore, obesity seems to be a risk factor for constipation. In addition, BMI is inversely correlated with constipation. ${ }^{34}$

Further, the current study showed significant improvement in the PAC-QOL scores of the patients, indicating that improvement in constipation symptoms improves the QOL. This is in agreement with a previous study which reported that increasing the intake of dietary fiber and the level of physical activity considerably improved constipation symptoms and QOL of their patients. ${ }^{35}$ Another study reported that chronic constipation negatively affects the QOL of the affected individual. ${ }^{2}$ This impact is more pronounced in women and at an advanced age; therefore, middle-aged women are more likely to be affected with constipation.

In this study, there were some limitations which are recommended to be addressed in future studies such as the ROM criteria, which is based on self-reported symptoms; therefore, there is a need to include an objective constipation assessment such as defecography. Furthermore, the current study proposed a physical activity program which needs more validation. Last, the participants' fluid intake was not covered in this study.

\section{Conclusion}

Increased physical activity positively affects the BMI, constipation complaints, and the QOL of premenopausal women. More effort and awareness are required to encourage an active lifestyle and dietary balance among different patients with constipation, especially women.

\section{Acknowledgment}

The authors would like to thank the patients of Cairo University Hospitals for their participation in the study.

\section{Disclosure}

The authors report no conflicts of interest in this work.

\section{References}

1. Mugie SM, Di Lorenzo C, Benninga MA. Constipation in childhood. Nat Rev Gastroenterol Hepatol. 2011;8(9):502-511.

2. Wald A, Scarpignato C, Kamm MA, et al. The burden of constipation on quality of life: results of a multinational survey. Aliment Pharmacol Ther. 2007;26(2):227-236.

3. Peppas G, Alexiou VG, Mourtzoukou E, Falagas ME. Epidemiology of constipation in Europe and Oceania: a systematic review. $B M C$ Gastroenterol. 2008;8:5.

4. Gwee KA, Ghoshal UC, Gonlachanvit S, et al. Primary care management of chronic constipation in Asia: the ANMA chronic constipation tool. J Neurogastroenterol Motil. 2013;19(2):149-160.

5. Heaton KW, Radvan J, Cripps H, Mountford RA, Braddon FE, Hughes AO. Defecation frequency and timing, and stool form in the general population: a prospective study. Gut. 1992;33(6):818-824.

6. Preston DM, Lennard-Jones JE. Severe chronic constipation of young women: 'idiopathic slow transit constipation'. Gut. 1986;27(1):41-48.

7. Leung L, Riutta T, Kotecha J, Rosser W. Chronic constipation: an evidence-based review. J Am Board Fam Med. 2011;24(4):436-451.

8. Rees WD, Rhodes J. Altered bowel habit and menstruation. Lancet. 1976;1:475.

9. Wald A, Van Thiel DH, Hoechstetter L, et al. Gastrointestinal transit: the effect of the menstrual cycle. Gastroenterology. 1981;80(6):1497-1500.

10. Lawson M, Kern F Jr, Everson GT. Gastrointestinal transit time in human pregnancy: prolongation in the second and third trimesters followed by postpartum normalization. Gastroenterology. 1985;89(5):996-999.

11. Hinds JP, Stoney B, Wald A. Does gender or the menstrual cycle affect colonic transit? Am J Gastroenterol. 1989;84(2):123-126.

12. Gonenne J, Esfandyari T, Camilleri M, et al. Effect of female sex hormone supplementation and withdrawal on gastrointestinal and colonic transit in postmenopausal women. Neurogastroenterol Motil. 2006;18(10):911-918.

13. de Oliveira EP, Burini RC. The impact of physical exercise on the gastrointestinal tract. Curr Opin Clin Nutr Metab Care. 2009;12(5):533-538.

14. Huang R, Ho SY, Lo WS, Lam TH. Physical activity and constipation in Hong Kong adolescents. PLoS One. 2014;9(2):e90193.

15. Tantawy SA, Kamel DM, Aziz AA, AbuFarha ME. Effect of weight reduction on liver enzyme in obese post-menopausal women with chronic hepatitis. Bull Fac Ph Th Cairo Univ. 2010;15(2):17-23.

16. Bi L, Triadafilopoulos G. Exercise and gastrointestinal function and disease: an evidence based review of risks and benefits. Clin Gastroenterol Hepatol. 2003;1(5):345-355.

17. Leitzmann MF, Giovannucci EL, Rimm EB, et al. The relation of physical activity to risk for symptomatic gallstone disease in men. Ann Intern Med. 1998;128(6):417-425.

18. Simrén M. Physical activity and the gastrointestinal tract. Eur J Gastroenterol Hepatol. 2002;14(10):1053-1056.

19. Kamel DM, Abd El-Raoof NA, Tantawy SA, El-Begawy AF, Abosaif NY. Does aerobic exercise training with weight loss affect serum C-reactive protein in asymptomatic obese peri-menopausal women? Bull Fac Ph Th Cairo Univ. 2008;13(1):127-135.

20. Casey E, Mistry DJ, MacKnight JM. Training room management of medical conditions: sports gastroenterology. Clin Sports Med. 2005;24(3):525-540, viii.

21. Iovino P, Chiarioni G, Bilancio G, et al. New onset of constipation during long-term physical inactivity: a proof-of-concept study on the immobility-induced bowel changes. PLoS One. 2013;8(8):e72608. 
22. Bengi G, Yalçın M, Akpınar H, Keskinoğlu P, Ellidokuz H. Validity and reliability of the patient assessment of constipation quality of life questionnaire for the Turkish population. Turk $J$ Gastroenterol. 2015;26(4):309-314.

23. McCrea GL, Miaskowski C, Stotts NA, Macera L, Hart SA, Varma MG. Review article: self-report measures to evaluate constipation. Aliment Pharmacol Ther. 2008;27(8):638-648.

24. Frank L, Farup C, Jones R, Miner P, Taylor L, Kleinman L. Evaluation of a patient symptom measure for constipation. Gastroenterology. 1998;114: A14.

25. Slappendel R, Simpson K, Dubois D, Keininger DL. Validation of the PAC-SYM questionnaire for opioid-induced constipation in patients with chronic low back pain. Eur J Pain. 2006;10(3):209-217.

26. Marquis P, De La Loge C, Dubois D, McDermott A, Chassany O. Development and validation of the patient assessment of constipation quality of life questionnaire. Scand J Gastroenterol. 2005;40(5):540-551.

27. Clayson DJ, Wild DJ, Quarterman P, Duprat-Lomon I, Kubin M, Coons SJ. A comparative review of health-related quality-of-life measures for use in HIV/AIDS clinical trials. Pharmacoeconomics. 2006;24(8):751-765.

28. Haywood KL, Garratt AM, Fitzpatrick R. Quality of life in older people: a structured review of generic self-assessed health instruments. Qual Life Res. 2005;14(7):1651-1668.

29. McHorney CA, Ware JE Jr, Lu JF, Sherbourne CD. The MOS 36-item Short-Form Health Survey (SF-36): III. Tests of data quality, scaling assumptions and reliability across diverse patient groups. Med Care. 1994;32(1):40-66.

30. Leone MA, Beghi E, Righini C, Apolone G, Mosconi P. Epilepsy and quality of life in adults: a review of instruments. Epilepsy Res. 2005;66(1-3): 23-44.

31. Neelakantan D, Omojole F, Clark TJ, Gupta JK, Khan KS. Quality of life instruments in studies of chronic pelvic pain: a systematic review. J Obstet Gynaecol. 2004;24(8):851-858.

32. De Schryver AM, Keulemans YC, Peters HP, et al. Effects of regular physical activity on defecation pattern in middle-aged patients complaining of chronic constipation. Scand J Gastroenterol. 2005;40(4):422-429.
33. Barololoum H. Effects of regular walking on chronic idiopathic constipation. Rep Opin. 2012;4(1):52-57.

34. Dukas L, Willett WC, Giovannucci EL. Association between physical activity, fiber intake, and other lifestyle variables and constipation in a study of women. Am J Gastroenterol. 2003;98(8):1790-1796.

35. Nour-Eldein H, Salama HM, Abdulmajeed AA, Heissam KS. The effect of lifestyle modification on severity of constipation and quality of life of elders in nursing homes at Ismailia city, Egypt. J Family Community Med. 2014;21(2):100-106.

36. Peters HP, De Vries WR, Vanberge-Henegouwen GP, Akkermans LM. Potential benefits and hazards of physical activity and exercise on the gastrointestinal tract. Gut. 2001;48(3):435-439.

37. Jennings A, Davies GJ, Costarelli V, Dettmar PW. Dietary fibre, fluids and physical activity in relation to constipation symptoms in preadolescent children. J Child Health Care. 2009;13(2):116-127.

38. El-Salhy M, Svensen R, Hatlebakk JG, Gilja OH, Hausken T. Chronic constipation and treatment options (Review). Mol Med Rep. 2014;9(1): 3-8.

39. Chin A Paw MJ, van Poppel MN, van Mechelen W. Effects of resistance and functional-skills training on habitual activity and constipation among older adults living in long-term care facilities: a randomized controlled trial. BMC Geriatr. 2006;6:9.

40. Derbyshire E, Davies J, Costarelli V, Dettmar P. Diet, physical inactivity and the prevalence of constipation throughout and after pregnancy. Matern Child Nutr. 2006;2(3):127-134.

41. Daley AJ, Grimmett C, Roberts L, et al. The effects of exercise upon symptoms and quality of life in patients diagnosed with irritable bowel syndrome: a randomised controlled trial. Int J Sports Med. 2008;29(9):778-782.

42. Gibson GR, Scott KP, Rastall RA, et al. Dietary prebiotics: current status and new definition. Food Sci Technol Bull Funct Foods. 2010;7(1): $1-19$.

43. Sanjoaquin MA, Appleby PN, Spencer EA, Key TJ. Nutrition and lifestyle in relation to bowel movement frequency: a cross-sectional study of 20630 men and women in EPIC-Oxford. Public Health Nutr. 2004;7(1):77-83.

\section{Publish your work in this journal}

Diabetes, Metabolic Syndrome and Obesity: Targets and Therapy is an international, peer-reviewed open-access journal committed to the rapid publication of the latest laboratory and clinical findings in the fields of diabetes, metabolic syndrome and obesity research Original research, review, case reports, hypothesis formation, expert opinion and commentaries are all considered for publication. The manuscript management system is completely online and includes a very quick and fair peer-review system, which is all easy to use. Visit http://www.dovepress.com/testimonials.php to read real quotes from published authors. 